\title{
OS MANUAIS DE EDUCAÇÃO E O DEBATE SOBRE A INFÂNCIA NA SEGUNDA METADE DO SÉCULO XIX, NO BRASIL
}

\author{
Mariana de Aguiar Ferreira Muaze ${ }^{1}$
}

\section{A Descoberta da Infância}

Resumo: Pretendo demonstrar que com consolidação do Estado Imperial, no Brasil, a educação e a instrução das crianças pertencentes à elite assumiriam o papel estratégico de introduzir um habitus civilizado nas famílias da boa sociedade. Neste processo, os manuais de educação atuaram como veículos de disseminação dos novos modelos de comportamento que iriam preparar os futuros cidadãos.

Unitermos: História da Criança, Educação, Infância, Habitus.

A consolidação do Estado Imperial, levado a cabo pelos dirigentes Saquaremas, na década de 1840, tinha como pressupostos básicos a manutenção da ordem, que significava a permanência das relações sociais baseadas na hierarquia e na escravidão, e a difusão da civilização, que pretendia elevar o Império à categoria de "nação civilizada" a exemplo da Europa, principalmente, de países como a França e a Inglaterra. Deste modo, a centralização deveria se dar tanto em termos políticoadministrativos, quanto socio-culturais.

Assim, durante o processo de consolidação do Império, tornou-se necessário estabelecer bases mais sólidas e

\footnotetext{
${ }^{1}$ Mestre em História Social da Cultura pela Pontifícia Universidade Católica do Rio de Janeiro.
}

Hist. Ensino, Londrina, v. 6, p. 57-71, out. 2000 
duradouras, que agissem na forma dos indivíduos de encarar o mundo. Ou seja, era urgente a criação de padrões de comportamento e códigos de sentido que delimitassem e apreendessem o real de uma forma comum, constituindo valores próprios à boa sociedade, além de uma maior identidade entre os membros do mundo do governo. ${ }^{2}$

A educação e a instrução das crianças pertencentes à elite assumiriam o papel estratégico de introduzir um novo habitus, dito civilizado, nas famílias da boa sociedade. ${ }^{3}$ O Estado Imperial almejava formar, de uma só vez, futuros cidadãos e membros do mundo do governo mais identificados culturalmente com seus referenciais de ordem e civilização. Esta valorização recaía sobre o período da infância por ser esta a fase da vida a qual os indivíduos sintonizam-se mais facilmente com um padrão de comportamento, incorporando-o como uma segunda natureza, um habitus.

Neste contexto, a segunda metade do século XIX, no Brasil, foi marcada por um processo de valorização da infância, que seria transformada no centro das atenções das famílias e no objeto de investimento do Estado. Sua educação, saúde e instrução tornaram-se motivo de discussão entre médicos, professores, religiosos e membros do governo, revelando uma

\footnotetext{
${ }^{2}$ Segundo llmar Mattos, a sociedade brasileira do século XIX era marcada por elementos de exclusão social, pautados na negação da liberdade e da propriedade. No topo da hierarquia social estava a boa sociedade formada por homens livres, da raça branca e proprietários de escravos. À boa sociedade eram atribuídas a capacidade e a competência para govemar a si própria e ao conjunto da sociedade, fazendo com que seus membros também estivessem no mundo do govemo. MATTOS, I. R. O Tempo Saquarema - A Formação do Estado Imperial. $2^{\mathrm{a} e d, ~ S P: ~ H u c i t e c, ~} 1990$.

${ }^{3}$ As análises, realizadas neste estudo, acerca do habitus como forma de identidade de grupo estão pautadas nas análises do sociólogo alemão Norbert Elias. Segundo ele, habitus é uma forma de sentir e agir não reflexiva, o equivalente a uma segunda natureza, que, por meio da disciplinarização das pulsões e do autocondicionamento psíquico, vai incorporando-se à estrutura da personalidade do indivíduo. ELIAS, N. A Sociedade da Corte. Lisboa: Estampa, 1995; Processo Civilizador. SP: JZE, 1993.v 2.

define-se como a consciência da particularidade infantil, e a percepção dos atores sociais
} 
mudança em relação ao contexto histórico precedente. ${ }^{4}$ Portanto, tratava-se de um despertar da sociedade imperial oitocentista em relação às particularidades da infância e aos cuidados diferenciados de que ela necessita, configurando, assim, um processo de "descoberta da infância". 5

Analisando os jornais de instrução e recreio, de grande circulação entre a boa sociedade da Corte e regiões circunvizinhas, também é possível identificar este movimento através de uma vasta gama de máximas, pensamentos e conselhos a respeito das crianças e de seus parâmetros educativos. Estas publicações periódicas, continham tanto artigos teóricos e reflexivos, de tom pedagógico, voltados aos pais e educadores, quanto sugestões práticas para o divertimento infantil. Tratavam-se de histórias e contos morais, jogos educativos, brincadeiras e brinquedos, que pretendiam, de maneira lúdica, formar as crianças.

A educação da infância seria, assim, uma das formas de levar adiante o projeto político do Império de difundir o modelo europeu de civilização. Compreendida de três formas complementares - educação física, educação moral e instrução - a educação assumiria o papel de garantir as "luzes" e o progresso, elevando o Brasil ao patamar das nações civilizadas. Portanto, as famílias que quisessem se ver reconhecidas como

\footnotetext{
${ }^{4}$ A respeito da familia patriarcal rural que marcou o período colonial e as primeiras décadas do Império, compartilho da idéia de Freyre a qual a hierarquia e o recurso da violência faziam parte das relações intrafamiliares. O pai, figura central, exercia sua forte autoridade em relação à esposa, aos filhos e demais familiares, e aos escravos, sempre convivendo próximos ao núcleo familiar. Determinando uma pouca intimidade e grande distância, em temos de relações afetivas. FREYRE, G. Casa Grande e Senzala. $25^{\mathrm{a}} \mathrm{ed}$, Rio de Janeiro: José Olympio, 1987.

${ }^{5}$ A noção de descoberta da infância, aqui recuperada, foi desenvolvida por Philippe Ariès. Segundo ele, este processo, ocorrido tardiamente nas sociedades ocidentais, de que a criança se diferencia do ser adulto. Assim, defende que a infância deve ser tratada como um conceito histónico, pois cada sociedade terá a sua forma de vivenciar e de lidar com esta experiência de acordo com a sua mentalidade e organização econômica. ARIÈS, P. História Social da Criança e da Familia. RJ: Guanabara, 1981.
}

Hist. Ensino, Londrina, v. 6, p. 57-71, out. 2000 
pertencentes à boa sociedade deveriam guiar-se conforme estes novos valores.(Muaze, 1999)

\section{Os Manuais de educação como veículos de difusão de um Habitus civilizado}

Diversos veículos figuraram como divulgadores dos padrões civilizados de comportamento, tais como: as revistas de modas, a literatura, os jornais de instrução e recreio, os manuais de etiqueta, os manuais de educação da infância e os ensinamentos escolares. Neste artigo, foram escolhidos para estudo, os manuais ou obras de literatura normativa, devido à sua grande importância no período. Eram livros especializados em educação, que alcançaram elevados índices de venda, obtendo inúmeras publicações, nacionais e importadas, e edições repetidas. Isso demonstra que o habitus descrito nestes manuais acabaria por nortear, direta ou indiretamente, o modelo comportamental eleito pela boa sociedade e pela classe dirigente.

Ao analisar estes manuais, achei por bem dividi-los em dois gêneros distintos: os livros de civilidade e de etiqueta e os manuais para educação física e moral dos meninos. ${ }^{6}$ Nascidos na Europa durante os séculos XV e XVI, os livros de civilidade e de etiqueta, eram dedicados ao "savoir vivre". Seu surgimento relaciona-se com o contexto sociopolítico de transformação da nobreza guerreira em nobreza de corte e com a centralização do poder político na figura do rei. No novo espaço da Sociedade de Corte, a etiqueta foi adquirindo um tom cada vez mais

${ }^{6}$ Esta divisão foi feita depois de um levantamento bibliográfico e temático das obras existente, na Biblioteca Nacional, IHGB, Museu Imperial de Petrópolis e Casa Rui Barbosa. Sobre este tema, cito os estudos de SCHWARCZ, Lilia Moritz. As Barbas do Imperador - D. Pedro II, um monarca nos trópicos. São Paulo: Cia das Letras, 1998; ROQUETTE, J. I - Código do Bom-Tom, ou, Regras de Civilidade e de bem viver no século XIX; organização Lilia Moritz Schwarcz. São Paulo: Cia das Letras, 1997- (Retratos do Brasil). 
minucioso, disciplinando os pequenos detalhes da vida social e cotidiana, regulando as pulsões e as condutas mais íntimas dos indivíduos. Deste modo, os detalhes do "savoir vivre" atuavam como uma forma de diferenciação social e de manutenção do prestígio. $^{7}$

No caso brasileiro, estes livros de civilidade e etiqueta chegariam juntamente com as muitas novidades trazidas pela Corte portuguesa. No entanto, a maior circulação de suas idéias dar-se-ia na segunda metade do século XIX. A partir de então, atingiram uma grande vendagem, podendo ser encontrados em bibliotecas ilustres como a da imperatriz Thereza Christina e em anúncios recorrentes nos diversos jornais. ${ }^{8}$ No Império, esse gênero literário apresentou grande aceitação social. Suas edições foram repetidas inúmeras vezes, seja em português ou em língua estrangeira. Concebidos como guias, escolas do mundo, continham normas da arte de comportar-se socialmente nas mais diversas ocasiões. Além disto, sua estrutura original dava ao leitor a possibilidade de ir diretamente ao tema selecionado, o que privilegiava uma leitura rápida e objetiva.

O segundo gênero de literatura tornou-se cada vez mais comum a partir dos escritos de Jean Jacques Rousseau em Emílio - ou da Educação. Os manuais para educação física e moral dos meninos eram dedicados, exclusivamente, à infância. Geralmente extensos, continham tanto recomendações sobre

\footnotetext{
7 Sobre o processo civilizador, Norbert Elias conduz seu raciocínio dizendo que a sociedade de corte e a nobreza que a compunha estavam imbuídas de uma racionalidade própria que super valorizava o luxo e colocava a etiqueta como principal forma de extemar a posição social dos indivíduos. Deste modo, com a complexificação das funções sociais, a etiqueta foi se tomando mais rigorosa e minuciosa até constituir-se em movimento perpétuo e autônomo. ELIAS, N. O Processo Civilizador. SP: JZE, 1994. v I.

${ }^{8} \mathrm{O}$ jomal O Correio das Damas, publicado em Lisboa durante os anos de 1836 a 1850 e circulante na Corte, fazia propaganda de manuais de etiqueta tais como: $A$ Arte de Conhecer os Homens pelos Gestos, Actitudes e Andar que era encontrado na livraria Bordallo por 600 réis. (O Correio das Damas. Tomo V, 1842) E o Manual de Civilidade e Etiqueta vendido na Corte, aos cuidados do Sr. Laemmert por 480 réis ( $O$ Correio das Damas. Tomo VIII, 1849).
}

Hist. Ensino, Londrina, v. 6, p. 57-71, out. 2000 
os cuidados físicos e de higiene na infância (educação física), quanto ensinamentos morais e pedagógicos (educação moral). ${ }^{9}$

Apesar de diferenciados, estes dois tipos de literatura atuam complementarmente mesmo que em campos distintos. Os manuais infantis deveriam ser lidos e seus ensinamentos colocados em prática, para que após bem formar e criar a infância, em uma fase posterior, os meninos e meninas aprendessem a arte do "savoir vivre" etiqueta para portarem-se dignamente nos diferentes espaços de sociabilidade. Assim, já adultos, treinados numa etiqueta condigna, os homens poderiam assumir os cargos na política e na administração pública, que o estatuto social de suas famílias lhe permitisse, e as esposas saberiam acompanha-los com a devida pompa e destreza social.

A idéia de transformação do mundo social, levada a cabo pela filosofia iluminista, estava ligada à educação, que passava a ser entendida como um instrumento propiciador de uma mudança na moral e na política da sociedade. $O$ pensamento ilustrado tinha um caráter pedagógico, por acreditar que a difusão do saber - "esclarecimento" - era capaz de criar um novo tipo de homem orientado por valores que não fossem mais os da tradição religiosa.

Entre os autores modernos, John Locke foi um dos primeiros a discutir a educação, considerando-a fundamental na formação de um homem com domínio sobre seus desejos e inclinações e com capacidade para exercer sua liberdade e desenvolver suas potencialidades. Segundo ele, era necessário enfatizar a educação daqueles destinados a serem os homens públicos, pois, educando os futuros encarregados das funções

\footnotetext{
${ }^{9}$ Os manuais de educação infantil traziam uma estrutura pré definida. Iniciavam-se com as regras sobre a educação física, ou arte de bem formar o corpo. Incluía-se, neste capítulo, tudo que dizia respeito a higiene, desde a fase do nascimento até a idade de dez a doze anos. Em seguida, vinham os preceitos de uma educação moral, onde figuravam as discussões pedagógicas sobre a formação do caráter infantil. MUAZE, M. A descoberta da infância e a construção de um habitus civilizado na boa sociedade imperial. RJ: PUC, 1999, dissertação de mestrado.
} 
governamentais, eles saberiam como ordenar o todo social. Portanto, Locke operava com uma concepção mais restrita da educação, segundo a qual a elite seria prioridade.(Filho, 1992) Nesta perspectiva, diferenciava-se de uma concepção de "educação para todos" como seria defendida por outros iluministas como Helvetius e Condorcet. ${ }^{10}$

Vista sob a ótica iluminista, a finalidade da educação é muito mais ampla do que a simples instrução, entendida como aquisição de conteúdos. Envolvia pretensões de moralizar e de tornar acessível os princípios que deveriam reger a sociedade. $O$ pensamento de Rousseau, assim como o de Helvetius e Condorcet, caminhava na defesa da popularização do saber, mas de forma diferenciada. Rousseau questionava a positividade do progresso e do intelectualismo. Segundo ele, o progresso científico e técnico, tão peculiar a cultura moderna, estaria longe de garantir um igual avanço no âmbito da moralidade e da felicidade. Da mesma forma, o intelectualismo e as luzes não garantiriam, em si, uma virtude moral e uma felicidade.(Fernandez, 1985)

Partindo desse pressuposto, Rousseau elege não a razão, mas a "voz da consciência" e o "testemunho interno" como fundamentadores da educação moral.(Starobinsk, 1991) Sua concepção propõe como princípio básico, o respeito pelas inclinações e pela liberdade do educando. Desta forma, as aptidões se desenvolveriam naturalmente, sem imposições autoritárias, ideológicas ou éticas, evitando que a criança fosse corrompida pela artificialidade social. Dentro de sua perspectiva, criticava as práticas educacionais que igualavam o aprendizado do adulto ao da criança, buscando respaldo na seguinte filosofia:

\footnotetext{
${ }^{10}$ O idealismo educativo de Helvetius considerava que a sociedade, em favor da felicidade e da prosperidade, aceitaria uma reforma profunda da educação. Condorcet, o maior defensor da idéia de progresso, concebia a educação como criadora da liberdade e igualdade entre os cidadãos. Desta forma, para eles, havia uma ligação entre educação, política e formação de bons cidadãos. FERNANDEZ, A. G., La llustracion Francesa. entre Voltaire y Rousseau. Madri: Gincel, 1985.
}

Hist. Ensino, Londrina, v. 6, p. 57-71, out. 2000 
A natureza quer que as crianças sejam crianças antes de serem homens. Se quisermos perverter esta ordem, produziremos frutos temporões, que não estão maduros, não têm sabor, e não tardaram em se corromper; teremos jovens doutores e crianças velhas. A infância tem maneiras de ver, de pensar e de sentir que the são próprias; nada é menos sensato do que tentar substituir essas maneiras pelas nossas.(Rousseau, 1985, p.86)

Portanto, a particularidade da infância era encarada como uma vontade da natureza. Subvertê-la seria o mesmo que pular etapas no desenvolvimento infantil, criando, portanto, uma educação artificial, não correspondente à especificidade da criança. Tal formação corruptora era vista por Rousseau como um elemento de desvio do homem de sua bondade natural, gerando vícios morais que o marcariam para sempre ao longo de sua vida.

Elizabeth Bandinter e Edward Shorter concordam ao dizerem que as concepções rousseaunianas sobre educação física e moral, mesmo que não seguidas à risca na prática cotidiana, foram importantes no sentido de trazer à cena discussões que elevariam a educação da infância a um patamar nunca antes alcançado.(Bandinter, 1985; Shorter, 1975) Diante disso, os séculos XVIII e XIX, na Europa, tornaram-se palco de uma proliferação de obras que incitam a preservação da moralidade e a educação da infância e concitam aos pais o amor natural e a convivência cotidiana com os filhos. ${ }^{11}$ Mas, se no que diz respeito à educação física, as sugestões de Rousseau seriam amplamente acatadas, principalmente pelo discurso médico-científico, o mesmo não ocorreria com o tema da moral.

\footnotetext{
${ }^{11}$ Anteriormente a uma literatura normativa estritamente relacionada à infância, que terá grande impulso no século XVIII, já havia obras de etiqueta e manuais de boa conduta que divulgavam o comportamento nobre e cortês para adultos e crianças. Dentre os livros pioneiros cito, no século XVI, Erasmo de Roterdam. ELIAS, N. op. cit.
} 
Contudo, os manuais de educação colocavam a infância como o centro das atenções tanto da família, como do Estado. Porém, na sociedade imperial, como se apresentariam estas questões acerca da educação da infância?

As discussões em torno da temática da infância e dos cuidados com sua educação, a partir da segunda metade do século passado, cresceriam, fazendo com que estes manuais também proliferassem no Império brasileiro. Se no início eram, na maioria, importados da França e de Portugal, pouco a pouco, vão surgindo as edições de autores nacionais. Este fato demonstra que a boa sociedade tornava-se fiel consumidora de seus valores e códigos de comportamento. Porém, as obras brasileiras apresentavam novidades e sofreriam adaptações conforme nossa realidade. Um bom exemplo era a substituição das normas para a escolha de uma ama-de-leite branca, como ocorria na Europa, por regras referentes à seleção da melhor escrava para o aleitamento. Em relação aos autores destas publicações, na maior parte, constituíam-se de médicos.(Alencastro, 1997)

Seja na forma de livros ou de artigos de jornais e revistas, a boa sociedade da Corte tinha acesso ao que se discutia na Europa, centro da civilização, em termos de educação e de habitus para a infância. Portanto, os manuais atuavam como difusores do habitus e como um espelho a ser seguido. Contudo, o reflexo em tal espelho apresentar-se-ia com uma expressão paradoxal, ocasionada pela junção de um habitus dito civilizado, transportado do modelo europeu, com uma sociedade baseada na hierarquia e na mão-de-obra escrava.

Para dar uma amostra da circulação dos manuais de educação da infância consultei alguns acervos privados. Na coleção da Imperatriz Thereza Christina, por exemplo, foi encontrado: $O$ Alforge da Boa Razão- livrinho para meninos e Éducation Physique de l'enfance, do médico August Sovet, Educazione Fisica, morale e intellettuale del fanciullo e O Educador da Mocidade Brasileira. A obra de L' Aimé Martin - Educação das Mães de Família, muito citada por autores brasileiros como uma referência - pertenceu à 
Maria Joaquina da Costa Botelho, esposa de Benjamim Constant. ${ }^{12} \mathrm{Em}$ coleções privadas de membros do Instituto Histórico e Geográfico Brasileiro estavam presentes L'Éducation de l'homme, De l'éducation e De l'éducation des filles - fables choisies de Fénelon ${ }^{13}$.

Sobre a concepção de educação contida nesta literatura normativa, pode-se apontar que havia uma diferenciação filosófica entre educação e ilustração. Em um ensaio na "Revista Popular", J. C. Fernandes Pinheiro escrevia:

Dirige-se a illustração ao espirito, é obra dos collegios: pode fazer eximios sabios, não fará, porém, bons cidadãos. Faz-nos a sciencia respeitador, e a educação queridos.(Pinheiro, 1859, p333)

O cronista, representando um pensamento comum entre os educadores da época, colocava que a educação seria uma tarefa essencialmente da família, e que abarcava as preocupações de bem formar o corpo e o moral de uma criança. Sob a influência do lluminismo, acreditava-se que a educação levaria ao progresso da nação e a felicidade individual, encarando-a como uma garantia de bons cidadãos para o Estado. Já a ilustração, dirigia-se ao espírito e ao intelecto, podendo ser ministrada no âmbito doméstico, com professores particulares, ou nos colégios, com a chamada educação coletiva, mais defendida na época pelos representantes do governo.

\footnotetext{
${ }^{12}$ SEABRA, B. O Alforge da Boa Razão - livninho para meninos. Rio de Janeiro, 1870; SOVET, A. Éducation

Physique de l'enfance. Bruxellas, Jamar, s/d; RECUPITO, Ippolito - Educazione fisica, morale ed Intelletuale. Tip del Cav Vecchi, 1886; MORAES, A. J. M. - O Educador da Mocidade Brasileira. Aprovada pelo arcebispo da Bahia para uso e leitura no Império. Bahia: Typ de Epiphanio Pedrosa. 1852. MARTIN, A. Educação das Mães e Familia. Traduzido do francês. 1834.

13 FROEBEL, F. L'Éducation de L'homme. Traduit de l'allemand par la baronne de Crombrugghe. $2^{\text {a }}$ ed, Paris: G Fischbacher, 1881; SPENCER, H. De l'éducation. Édition populaire. 2 $2^{\mathrm{a}}$ ed, Panis: Libranie Gemer Bailliére, s.d; FÉNELON. De l'Éducation des Filles. Fables choisies. Paris: Librarie bibliothèque nationale, 1885.
} 
Contudo, se na teoria educação e ilustração figuravam como conceitos distintos, ao que parece, na prática, a confusão entre estes dois era destacada constantemente, tanto nos manuais, quanto nos artigos de periódicos:

Ouvimos diariamente dizerem pais de familias: queremos dar aos nossos filhos boa educação, e para isso apressamo-nos em mandal-os ao collegio. E os que assim se exprimem, ignoram a rigorosa accepção dos dois vocabulos: (...) A educação precede a illustração, e é muito mais difficil de adquirir.(Pinheiro, 1859, p330)

É importante colocar que a educação era entendida como o legado primeiro e mais precioso que deveria ser deixado pela família. Por este motivo, a ilustração sem uma educação prévia ocasionaria vícios de caráter como o pedantismo e a afetação. Desta forma, os educadores compartilhavam da idéia de que: "Se fôr preciso escolher antes educação do que instrucção; antes moralidade do que sciencia; antes fazermos homens de bem do que sabichões". ${ }^{14} \mathrm{~A}$ educação era mais valorizada do que a ilustração, no que diz respeito à maioria da população. Mas, ao contrário, no que concerne as famílias da boa sociedade, era pressuposto básico que estes dois estágios fossem percorridos com êxito:

Entendemos que a educação é mais necessária do que a illustração: nem todos podem ser literatos, mas cumpre que ninguém ignore as regras necessárias, para ser estimado em sociedade.(Pinheiro, 1859, p333)

Os manuais pedagógicos, assim como os artigos de jornais, tratavam, principalmente, da educação. No entanto, faziam algumas incursões no tocante à ilustração ou educação

${ }^{14}$ CALOGERAS, J. B - Revista Popular - 1859-1862 - $1^{\circ}$ Anno - Tomo1. p. 95.

Hist. Ensino, Londrina, v. 6, p. 57-71, out. 2000 
intelectual, como também era chamada. Desta forma, mesmo se tratando de instâncias diferenciadas, educação e ilustração eram vistas como complementares no que diz respeito à educação da elite. Tal fato encontrava-se vinculado à um projeto mais amplo de criação de um "homem de luzes", "civilizado", portador de um corpo, de um moral, e de uma gama de conhecimentos condizentes com os seus direitos e deveres como cidadão. Vista sob este aspecto, a educação da infância no presente alcançava um significado de garantia de futuro não só da família como integrante da elite, mas do Império do Brasil, na sua caminhada em direção às nações civilizadas.

Portanto, havia a crença de que educando a criança, moral, física e socialmente, formar-se-ia um futuro cidadão condizente com os projetos do Império, e um integrante da boa sociedade, enquadrado nos valores de ordem e civilização. A educação infantil e a ilustração foram, então, selecionadas como símbolos de prestígio, que serviam para unir a boa sociedade, não somente em termos de propriedades e poder político, mas em torno de um habitus comum. Através de um novo padrão de comportamento, eleito como civilizado, a boa sociedade procurava diferenciar-se em relação à gente miúda e àqueles que não compartilhavam de seu status social. No sentido aqui exposto, a ênfase dada à educação pela filosofia iluminista era lida pelas elites brasileiras conforme seus interesses. Assim, na sociedade imperial, a educação atuaria muito mais como elemento de distinção do que de igualdade, como originalmente concebido.

Assim, os princípios educacionais pretendidos aproximavam-se mais dos formulados por Locke, que defendia a educação dos "gentlemen", membros da elite e futuros homens do governo. Entretanto, as finalidades desejadas eram díspares. Diferentes dos iluministas, os objetivos da educação no Império não incluíam nem uma crítica política ou moral da sociedade vigente, nem uma busca da igualdade social; mas sim um reforço das hierarquias sociais mediante valores e elementos de prestígio mais sutis. 
A valorização da instrução, incutida no projeto político do Império, procurava, a um só tempo, transformar a sociedade a partir dos ensinamentos de um novo habitus civilizado que tinha como modelo as nações européias; e conservar suas hierarquias sociais, definindo os lugares de súditos e de cidadãos, ou seja, dos que somente obedecem e dos que obedecem e participam politicamente.(Mattos, 1990)

O mesmo ocorria com a noção de cidadania que, ao ser importada para terras imperiais ficava limitada aos homens, brancos, livres e proprietários, acabando por ocasionar uma releitura de valores como igualdade e liberdade. Assim, a concepção iluminista que via a educação como fundamental para a formação do povo, e todas as suas implicações no sentido de valorização da infância chegaram ao Brasil. Contudo, o entendimento da noção de "povo" adquiriria um sentido bastante próprio, que o limitaria à boa sociedade.

\section{Bibliografia}

ALMEIDA, A. M. (org). Pensando a Família no Brasil-da colônia à modernidade. Rio de Janeiro: co-edição Espaço e Tempo/ UFRRJ, 1987.

ALENCASTRO, L. F. (org) História da Vida Privada no Brasil. São Paulo: Cia das Letras, 1997, v. II.

ARIĖ, P. História Social da Criança e da Família. RJ: Guanabara, 1981.

BANDINTER, E. O Mito do Amor Conquistado. Rio de Janeiro: Nova Fronteira, 1985.

CASSIRER, Ernest. A Filosofia do lluminismo. $2^{a}$ ed. São Paulo: UNICAMP, 1994.

CHARTIER, R. História Cultural - entre práticas e representações. Lisboa: Bertrand, 1990.

CLAYDON, L. F. Rousseau on Education. Londres: The Macmillian Company, 1969. 
ELIAS, N. A Sociedade de Corte. $2^{\text {a }}$ ed, Lisboa: Estampa, 1995. . Processo Civilizador. São Paulo: JZE, 1993. vol II. Processo Civilizador. São Paulo: JZE, 1994. vol I.

FILHO, J. Moral e História em John Locke. SP: Loyola, 1992. FERNANDEZ, A. G. La llustración Francesa - entre Voltaire y Rousseau. Madri: Gincel, 1985.

FREYRE, G. Sobrados e Mocambos. $8^{\mathrm{a}}$ ed, São Paulo: Record, 1990. . Casa Grande e Senzala. 25 a ed, Rio de Janeiro: José Olympio ed., 1987.

FREITAS, M. C. (org) História Social da Infância no Brasil. São Paulo: Cortez, 1997.

MATTOS, I. R. O Tempo Saquarema - A Formação do Estado Imperial. $2^{\mathrm{a} e d, ~ S P: ~ H u c i t e c, ~} 1990$.

MARKERT, W., (org.) Teorias de Educação do lluminismo. Rio de Janeiro: Tempo Brasileiro, 1994.

MAUAD, A. M. A Vida das Crianças de Elite durante o Império. 1998, (no prelo)

MUAZE, M.A. F. A descoberta da infância e a construção de um habitus civilizado na boa sociedade imperial. RJ: PUC, 1999, dissertação de mestrado.

PILOTTI, F. \& RIZZINI, I. A Arte de Governar Crianças. Rio de Janeiro: Anais, 1995.

PRIORE, M. Del (org). História da Criança no Brasil. São Paulo: Contexto, 1991.

RIZZINI, I. (org). Olhares sobre a Criança no Brasil - séculos $X I X$ e XX. Rio de Janeiro: Anais, 1997.

ROQUETTE, J. I - Código do Bom-Tom, ou, Regras de Civilidade e de bem viver no século XIX; organização Lilia Moritz Schwarcz. São Paulo: Cia das Letras, 1997- (Retratos do Brasil).

ROUSSEAU, J. J. Emílio ou Da Educação. São Paulo: Martins Fontes, 1995.

SCHWARCZ, Lilia Moritz. As Barbas do Imperador - D. Pedro II, um monarca nos trópicos. São Paulo: Cia das Letras, 1998. SHORTER, E. A Formação da Família Moderna. Lisboa: Terramar ed, 1975. 
STAROBINSKI, J. J. Jean-Jacques Rousseau - a transparência e o obstáculo. São Paulo: Cia das Letras, 1991 FONTES IMPRESSAS:

Correio das Damas - jornal de litteratura e modas. Lisboa, typografia Lisboense, editor J. S. Mengo, 1836-1850. (Biblioteca Nacional/sessão de obras raras).

FÉNELON. De l'Éducation des Filles. Fables choisies. Paris: Librarie bibliothèque nationale, 1885.

FROEBEL, F. L'Éducation de L'homme. Traduit de l'allemand par la baronne de Crombrugghe. $2^{\text {a }}$ ed, Paris: G Fischbacher, 1881. MARTIN, A. Educação das Mães e Família. Traduzido do francês. 1834.

MORAES, A. J. M. - O Educador da Mocidade Brasileira. Aprovada pelo arcebispo da Bahia para uso e leitura no Império. Bahia: Typ de Epiphanio Pedrosa. 1852.

RECUPITO, Ippolito - Educazione fisica, morale ed Intelletuale. Tip del Cav Vecchi, 1886.

Revista Popular - noticiosa, scientifica, industrial, histórica, litteraria, biographica, anedoctica, musical, etc. Rio de Janeiro: B. L. Garnier, 1859-1862. (Fundação Casa Rui Barbosa).

SEABRA, B. O Alforge da Boa Razão - livrinho para meninos. Rio de Janeiro, 1870

SPENCER, H. De l'éducation. Édition populaire. $2^{\mathrm{a}}$ ed, Paris: Librarie Germer Bailliére, s.d.

SOVET, A. Éducation Physique de l'enfance. Bruxellas, Jamar, s/d.

Abstract: I intend to show that with the consolidation of the Imperial State, in Brazil, the education of elite's children assumed the strategic duty of introduce a civilized habitus in the wealthy families. In that process, the books of education were a important spread of new behavior's models that would prepare future's citizens.

Keywords: Childhood History, Education, children, Habitus. 